\title{
Concurrent infection with dengue virus type-2 and DENV-3 in a patient from Ceará, Brazil
}

\author{
Fernanda Montenegro de Carvalho Araújo, Rita Maria Ribeiro Nogueira*/+, \\ Josélio Maria Galvão de Araújo*, Izabel Letícia Cavalcante Ramalho, \\ Maria Lucia Feitosa de Sá Roriz, Maria Elizabeth Lisboa de Melo, \\ Ivo Castelo Branco Coelho**
}

Laboratório Central de Saúde Pública do Ceará, Fortaleza, CE, Brasil *Laboratório de Flavivirus, Instituto Oswaldo Cruz-Fiocruz, Av. Brasil 4365, 21040-900 Rio de Janeiro, RJ, Brasil **Universidade Federal do Ceará, Fortaleza, CE, Brasil

Dengue outbreaks have occurred in several regions in Brazil and cocirculating dengue virus type 1 (DENV-1), $D E N V-2$, and DENV-3 have been frequently observed. Dual infection by DENV-2 and DENV-3 was identified by typespecific indirect immunofluorescence assay and confirmed by reverse transcription polymerase chain reaction in a patient in Ceará with a mild disease. This is the first documented case of simultaneous infection with DENV-2 and DENV-3 in Brazil. Sequencing confirmed DENV-2 and DENV-3 (South-East/American) genotype III and (SriLanka/ India), genotype III respectively.

Key words: dengue - concurrent infection - DEN2 - DENV-3 - Ceará - Brazil

Dengue is one of the most important arboviral infections affecting humans, caused by one of the four serotypes of dengue virus (DENV-1, 2, 3, 4). They belong to the genus Flavivirus, family Flaviviridae (Gubler 1998). The prevalence of this disease has grown in recent decades and is now endemic in more than 100 countries in Africa, the Americas, the Eastern Mediterranean, Southeast Asia, and the Western Pacific (Chaturvedi et al. 2004). Since 1986, dengue epidemics have been reported in Brazil, initially involving DENV-1 and after 1990, DENV-2. With the introduction of DENV- 3 in 2000, three serotypes are now circulating in Brazil (Nogueira et al. 2005). With the change in the epidemiological pattern that has occurred in approximately 30 years, the Americas, and more recently Brazil, can be considered a hyperendemic region, with multiple cocirculating serotypes. Since 1986, the state of Ceará began reporting dengue transmission with epidemic peaks in 1987, 1990, 1994, and 2001. Only DENV-1 was in circulation until 1994, when DENV-2 was introduced. This serotype caused a large epidemic with 47,789 notified cases, in which 14 deaths have been reported (Souza et al. 1995). In March 2002, DENV-3 was first isolated in Ceará by the Central Laboratory of Public Heath, thus it became an area of high endemicity with three cocirculating serotypes. Interestingly, in spite of the high or hyperendemicity of dengue viruses in some populations, relatively few cases of double infection have been reported (Gubler et al. 1985, Laille et al. 1991, Maneekarn et al. 1993, Sisouk et al. 1995). More recently two cases were reported in Brazil

Financial support: CNPq (501564/03-9), Faperj (E-26/152.490/ 2002), Funasa

${ }^{+}$Corresponding author: rita@ioc.fiocruz.br

Received 9 June 2006

Accepted 31 July 2006 involving DENV-1 DENV-2 (Santos et al. 2003). Simultaneous infection with DENV-2 and DENV-3 was reported by Kanesa-Thasan et al. (1994), by Wang et al. (2003) during an outbreak in Taiwan in 2000, and more recently by Wenming et al. (2005), who confirmed simultaneous infection with dengue 2 and 3 viruses in a Chinese patient returning from Sri Lanka.

A case of concurrent infection due to DENV-2 and DENV-3 was confirmed during an outbreak of dengue in the state of Ceará in the Northeastern region of Brazil in 2003. The patient was a 36 year-old male who lived in Tauá, a town of approximately 52,000 inhabitants, located $337 \mathrm{~km}$ far from Fortaleza city, the state capital. The onset of symptoms started on February 2, with high fever, headache, arthralgia, myalgia, retrobulbar pain, and asthenia. No hemorrhagic manifestation and no severe signs were observed, and the patient was fully recovery after one week. A mild disease, in spite of dual infection, has been observed by other authors and does not support the hypothesis that double infection with dengue viruses leads to more severe hemorrhagic disease (Gubler et al. 1985, Santos et al. 2003). Interestingly, DENV-2 and DENV-3 viruses have been well documented in severe cases in Brazil (Nogueira et al. 2001, 2005). The serum was obtained two days after the onset of symptoms and the procedures for virus isolation and virus identification were performed using the protocol previously described by Nogueira et al. (2001) using monoclonal antibodies. Polymerase chain reaction directly from the serum has been suggested in order to avoid selection of a dengue serotype during attempts of virus isolation in tissue culture. The present results show that both serotypes were identified, by the virus isolation process and by molecular method (Fig. 1).

For RNA extraction the supernatant of $\mathrm{C} 6 / 36$ was extracted using a QIAmp Viral Mini Kit (Qiagen, US) according to the manufacturer's protocol. Reverse transcription (RT-PCR) for detecting and typing DENV in acute sera and tissue culture fluid were carried out according to 


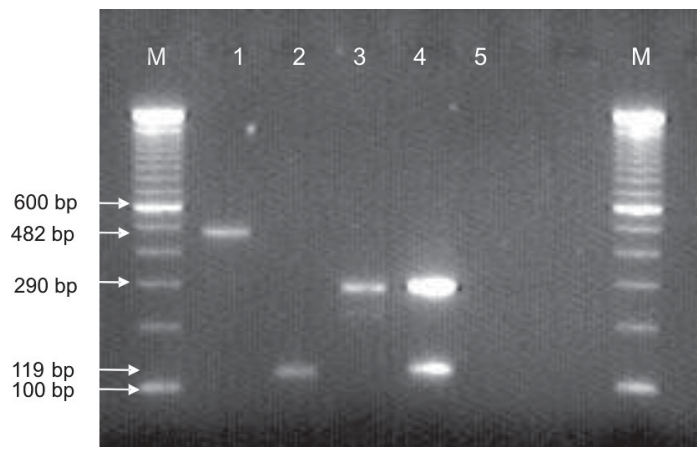

Fig. 1: M: 100-bp, ladder (Gibco). Lanes - 1: DENV-1 positive control; 2: DENV-2 positive control; 3: line DENV-3 positive control; 4: patient serum showing dual infection with DENV-3 and DENV-2; 5: negative control.

Lanciotti et al. (1992). Primers for sequencing DENV2 and DENV-3 were performed according to Rico-Hesse (1990) and Lanciotti et al. (1994), respectively.

Fig. 1 shows gel exhibiting two bands corresponding DENV-2 and DENV-3 viruses. Figs 2 and 3 show the phy- logenetic analysis of isolates corresponding to DENV2 E/NSI (Rico-Hesse 1990) and DENV-3 prM/M/E gene regions (Lanciotti et al. 1994). The genotypes found corresponded to genotype III (South-East/Asia) and genotype III (Indian Subcontinent) DENV-2 and DENV-3, respectively.

Vertical transmission is of great epidemiological importance and suggests that vector mosquitoes may play an important role in the maintenance (Castro et al. 2004) of virus in the environment and mosquitoes may act as reservoirs of these viruses (Joshi et al. 2006). Laboratory data demonstrated that the mosquito Aedes aegypti may be infected with double combinations of different arboviruses and that it is also capable of transmitting these viruses simultaneously. According to Wenming et al. (2005) it is possible to assume that mosquitoes infected with DENV-2 and DENV-3 may transmit them both in areas where two or more serotypes of the virus exists, together with a high prevalence of the vector.

In spite of both serotypes involved in this case can lead to severe form of dengue in Brazil, a dual infection did not caused a dengue severe clinical presentation in this patient. Understanding of the DHF pathogenesis is

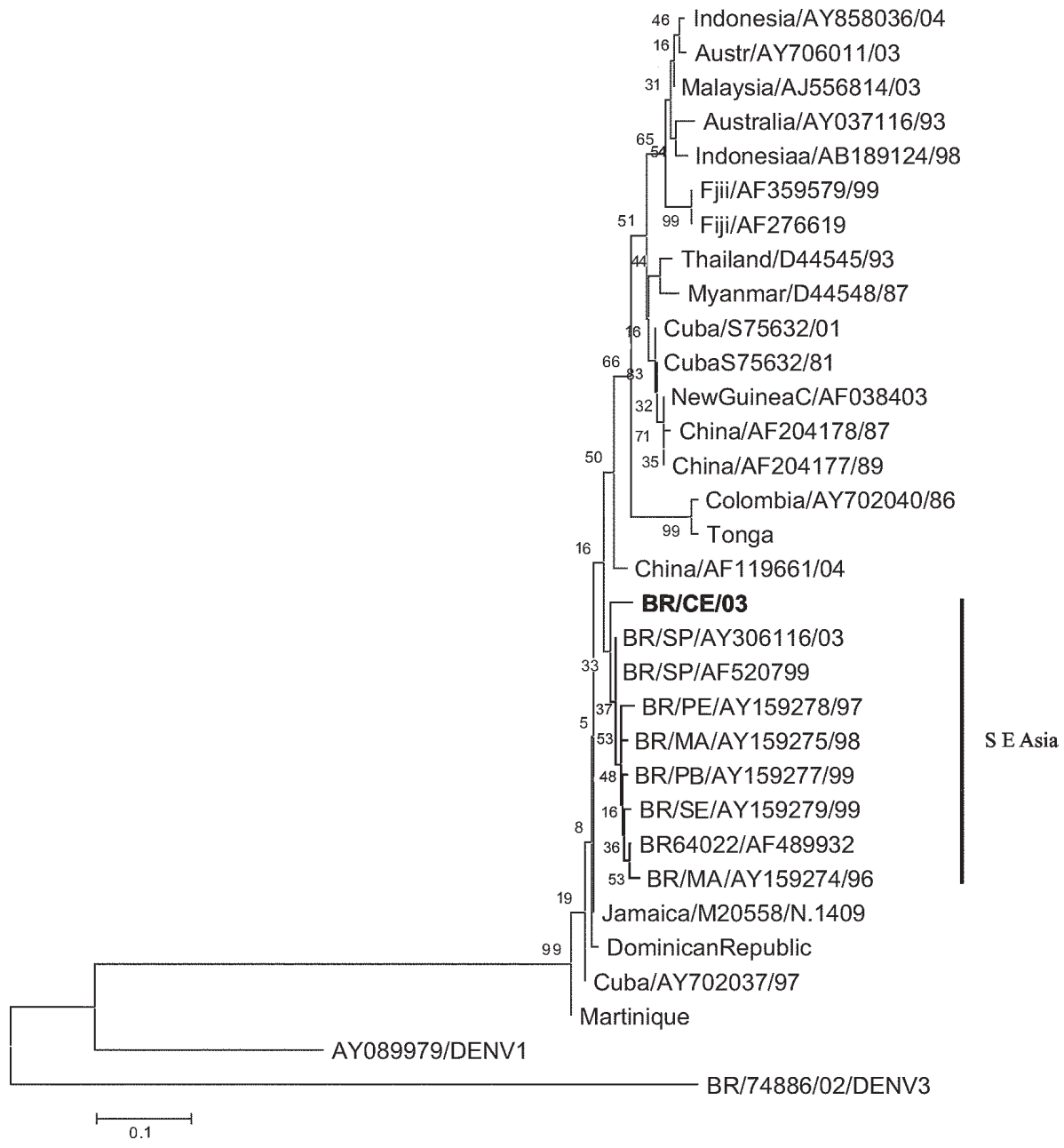

Fig. 2: phylogenetic analysis of 30 dengue viruses type 2 using 240 nucleotides from the E/NS1 junction. Representatives of the other serotypes were used as an out group; 1000 bootstrap replications were used to estimate the reliability of the predicted tree. 


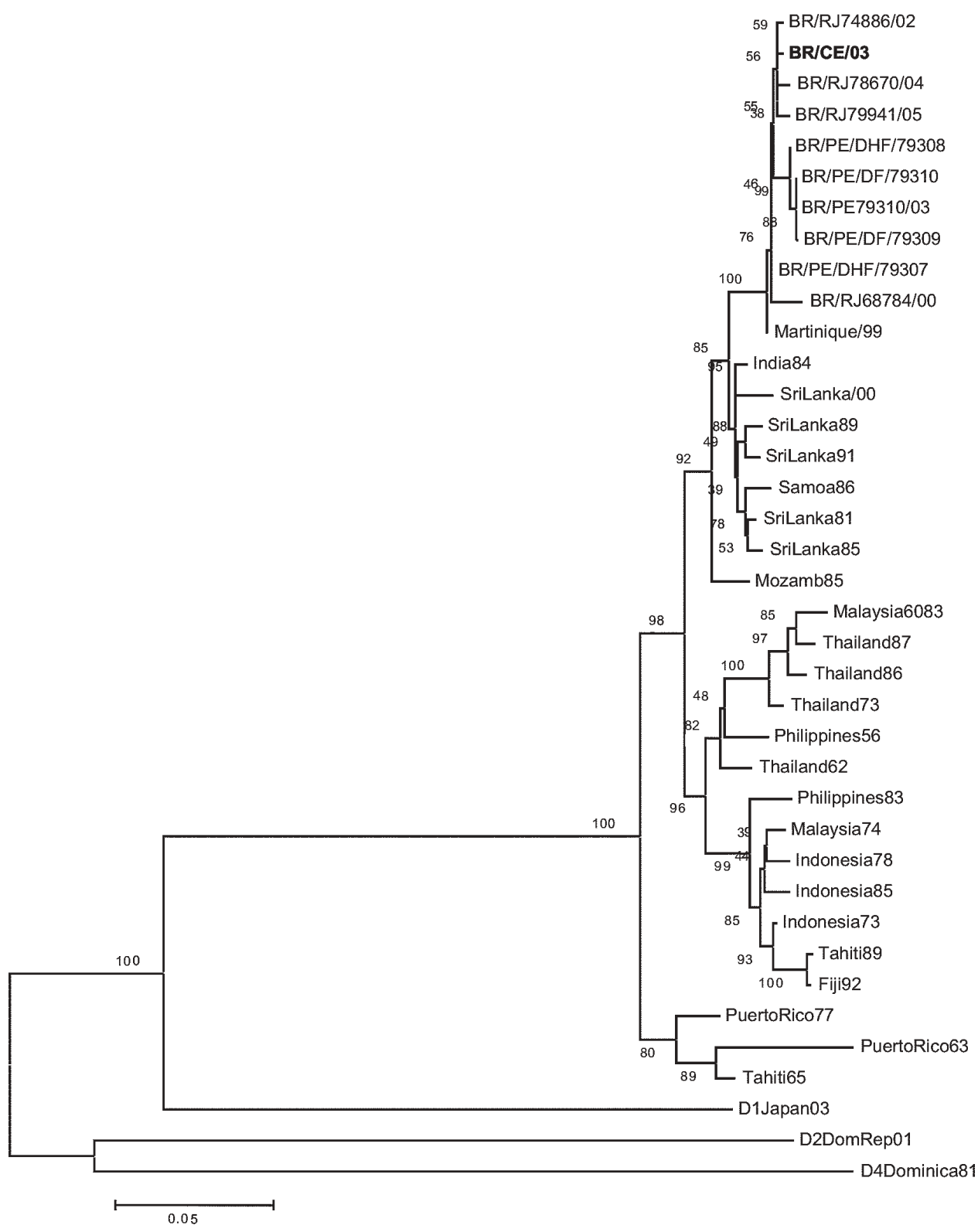

Fig. 3: phylogenetic analysis of 35 dengue viruses type 3 using 1976 nucleotides from the E gene. Representative of the other serotypes were used as an out group; 1000 bootstrap replications were used to estimate the reliability of the predicted tree.

not complete so far and two distinct hypotheses to explain the mechanism of DHF have been suggested. Immune responses and viral virulence have been considered as two major factors responsible for the pathogenesis (Kurane 2001). Serological tests showed a primary infection in this case; therefore it is plausible to admit that this case should be classified as dengue fever, which represents the majority of dengue infection.

This is the first documented case of dual infection with DENV-2 and DENV-3 in Brazil.

\section{REFERENCES}

Castro MG, Nogueira RM, Schatzmayr HG, Miagostovich MP, Lourenço-de-Oliveira R 2004. Dengue virus detection by using reverse transcription-polymerase chain reaction in saliva and progeny of experimentally infected Aedes albopictus from Brazil. Mem Inst Oswaldo Cruz 99: 809-814.

Chaturvedi UC, Shrivastava R. Dengue haemorrhagic fever: a global challenge 2004. Indian J Med Microbiol 22: 5-6.

Gubler DJ 1998. Dengue and dengue hemorrhagic fever. Clin Microbiol Rev 11: 480-496.

Gubler DJ, Kuno G, Sather GE, Waterman SH 1985. A case of natural concurrent human infection with two dengue viruses. Amer J Trop Med Hyg 34: 170-173.

Joshi V, Sharma RC, Sharma Y, Adha S, Sharma K, Singh H, Purohit A, Singhi M 2006. Importance of socioeconomic status and tree holes in distribution of Aedes mosquitoes (Diptera: 
Culicidae) in Jodhpur, Rajasthan, India. J Med Entomol 43: 330-336.

Kanesa-Thasan N, Iacono-Connors L, Magill A, Smoak B, Vaughn D, Dubois D, Burrous J, Hoke C 1994. Dengue serotypes 2 and 3 in US forces in Somalia. Lancet 343: 678.

Kurane I, Takasaki T 2001. Dengue fever and dengue haemorrhagic fever: challenges of controlling an enemy still at large. Rev Med Virol 11: 301-11.

Laille M, Deubel V, Saint-Marie FF 1991. Demonstration of concurrent dengue 1 and dengue 3 infection in six patients by polymerase chain reaction. J Med Virol 34: 51-54.

Lanciotti RS, Calisher CH, Gubler DJ, Chang GJ, Vordam AV 1992. Rapid detection and typing of dengue viruses from clinical samples by using reverse transcriptase-polymerase chain reaction. J Clin Microbiol 30: 545-551.

Lanciotti RS, Lewis JG, Gubler DJ, Trent DW 1994. Molecular evolution and epidemiology of dengue-3 viruses. J Gen Virol 75: 65-75.

Maneekarn N, Morita K, Tanaka M, Igarashi A, Usawattanakul W, Sirisanthana V, Innis BL, Sittisombut N, Nisalak A, Nimmanitya S 1993. Applications of polymerase chain reaction for identification of dengue viruses isolated from patient sera. Microbiol Immunol 37: 41-47.

Nogueira RMR, Miagostovich MP, Filippis AMB, Pereira MAS, Schatzmayr HG 2001. Dengue type 3 in Rio de Janeiro, Brazil. Mem Inst Oswaldo Cruz 96: 925-926.
Nogueira RM, Schatzmayr HG, Filippis AMB, dos Santos FB, Cunha RV, Coelho JO, Souza LJ, Guimarães FR, Araújo ESM, De Simone TS, Baran M, Teixeira Jr G, Miagostovich MP 2005. Dengue virus type 3, Brazil, 2002. Emerg Infect Dis 11: 1376-1381.

Rico-Hesse R 1990. Molecular evolution and distribution of dengue viruses type 1 and 2 in nature. Virology 174: 479-493.

Santos CLS, Bastos MAA, Sallum MAM, Rocco IM 2003. Molecular characterization of dengue viruses type 1 and 2 isolated from a concurrent human infection. Rev Inst Med Trop São Paulo 45: 11-16.

Sisouk T, Kanemura K, Saito M, Phommasack B, Makino Y, Arakaki S, Fukunaga T, Insisiengmay S 1995. Virological study on dengue epidemic in Vientiane municipality, Lao PDR, 1994. Jap J Trop Med Hyg 23: 121-125.

Souza RV, da Cunha RV, Miagostovich MP, Timbo MJ, Montenegro F, Pessoa ET, Nogueira RM, Schatzmayr HG 1995. An outbreak of dengue in the state of Ceara, Brazil. Mem Inst Oswaldo Cruz 90: 345-346.

Wang WK, Chao DY, Lin SR, King CC, Chang, SC 2003. Concurrent infections by two dengue virus serotypes among dengue patients in Taiwan. J Microbiol Immunol Infect 36: 8995.

Wenming P, Man Y, Baochang F, Yongqiang D, Tao J, Hongyuan D, Ede Q 2005. Simultaneous infection with dengue 2 and 3 viruses in a Chinese patient return from Sri Lanka. J Clin Virol 32: 194-198. 